\title{
Radioimmunotherapy Combined with Maintenance Anti-CD20 Antibody May Trigger Long-Term Protective T Cell Immunity in Follicular Lymphoma Patients
}

\author{
Franz Buchegger, ${ }^{1,2}$ Steven M. Larson, ${ }^{3}$ Jean-Pierre Mach, ${ }^{4}$ Yves Chalandon, ${ }^{5}$ \\ Pierre-Yves Dietrich, ${ }^{6}$ Anne Cairoli, ${ }^{7}$ John O. Prior, $^{1}$ Pedro Romero, ${ }^{8}$ and Daniel E. Speiser ${ }^{8}$ \\ ${ }^{1}$ Department of Nuclear Medicine, Lausanne University Hospital, 1011 Lausanne, Switzerland \\ ${ }^{2}$ Department of Nuclear Medicine, Geneva University Hospitals, 1211 Geneva, Switzerland \\ ${ }^{3}$ Department of Radiology, Memorial Sloan Kettering Cancer Center, New York, NY 10065, USA \\ ${ }^{4}$ Department of Biochemistry, University of Lausanne, 1066 Lausanne, Switzerland \\ ${ }^{5}$ Department of Hematology, Geneva University Hospitals, 1211 Geneva, Switzerland \\ ${ }^{6}$ Department of Oncology, Geneva University Hospitals, 1211 Geneva, Switzerland \\ ${ }^{7}$ Department of Oncology, Lausanne University Hospital, 1011 Lausanne, Switzerland \\ ${ }^{8}$ Ludwig Center, Department of Oncology, Lausanne University Hospital, 1011 Lausanne, Switzerland
}

Correspondence should be addressed to Franz Buchegger; franz.buchegger@chuv.ch

Received 1 October 2013; Revised 5 November 2013; Accepted 6 November 2013

Academic Editor: Michael H. Kershaw

Copyright (C) 2013 Franz Buchegger et al. This is an open access article distributed under the Creative Commons Attribution License, which permits unrestricted use, distribution, and reproduction in any medium, provided the original work is properly cited.

Growing evidence suggests that the patient's immune response may play a major role in the long-term efficacy of antibody therapies of follicular lymphoma (FL). Particular long-lasting recurrence free survivals have been observed after first line, single agent rituximab or after radioimmunotherapy (RIT). Rituximab maintenance, furthermore, has a major efficacy in prolonging recurrence free survival after chemotherapy. On the other hand, RIT as a single step treatment showed a remarkable capacity to induce complete and partial remissions when applied in recurrence and as initial treatment of FL or given for consolidation. These clinical results strongly suggest that RIT combined with rituximab maintenance could stabilize the high percentages of patients with CR and PR induced by RIT. While the precise mechanisms of the long-term efficacy of these 2 treatments are not elucidated, different observations suggest that the patient's T cell immune response could be decisive. With this review, we discuss the potential role of the patient's immune system under rituximab and RIT and argue that the T cell immunity might be particularly promoted when combining the 2 antibody treatments in the early therapy of FL.

\section{Long-Term Complete Remissions of FL Have Been Reported after Either RIT or Rituximab Treatment}

Advanced stage follicular lymphoma (FL) cannot be cured by standard chemotherapy [1]. In the frequently slow evolution of the disease, FL tends to become less responsive to chemotherapy, remissions lasting shorter time or the disease transforms to higher grade lymphoma. In recent years, it has been shown repeatedly that allogeneic hematopoietic stem cells transplantation (HSCT) can induce a plateau of tumor free survival and has a curative potential [2-4], suggesting that donor $\mathrm{T}$ cells bear the potential to cure FL patients [5].

The first, highly efficient anti-CD20 radioimmunotherapy (RIT) has been published in 1993 [6,7] and single agent rituximab (Mabthera, Rituxan, Roche Ltd, Genentech) treatments were published a few years later [8-11]. Long-term complete remissions (CR) lasting 8 years or more have since been reported after single agent rituximab as well as after RIT $[9,10,12-15]$. These sustained remissions might be a first indication of the curative potential of the 2 antibody based treatments. 
There is increasing evidence that the patient's T cells could be particularly involved in these long-term responses, as recently postulated in a letter to the editor [16]. The combination of the 2 treatments, as discussed here, with the particular aim to preserve, stimulate, and study the patient's $\mathrm{T}$ cell response would appear attractive notably when being initiated as first line or early treatment of FL.

\section{The Patient's Immune Response May Be Relevant to Long-Term Tumor Control of FL}

The tumor microenvironment shows remarkable adaptations in FL [17]. Tumor cells interact with stromal cells allowing the promotion of tumor growth [18-20]. Cytotoxic T lymphocytes were shown to have a tumor controlling potential, but, once they are present in the tumor microenvironment, they may be inhibited by regulatory $\mathrm{T}$ and/or B cells [21-25] or exhausted as shown in melanoma [26] and lymphoma [27].

Conversely, immune response signatures have identified tumor infiltrating $\mathrm{T}$ cells, monocytes, and dendritic cells as being predictive of survival of FL [28]. RT-PCR based gene expression profiling results were in agreement with these observations [29]. Interestingly, high numbers of tumor infiltrating FOXP3 positive regulatory T cells were also predictive of improved overall survival [30]. The nature as well as the potential heterogeneity of regulatory $\mathrm{T}$ cells remains, however, controversial $[31,32]$. Recently, follicular Th cells in the tumor microenvironment have also been implicated in promoting immunosuppression [33]. Thus, contradicting roles have been observed for tumor infiltrating stromal cells [32].

Under rituximab treatment elimination of regulatory $B$ cells $\left(B_{\text {reg }}, B 10\right)$ could be an explanation for the observation of favorable $\mathrm{T}$ cell responses [24, 34]. Different groups have also studied at the preclinical and clinical level the efficacy of blocking T-cell inhibitory receptors [35]. Anti-CTLA-4 $[25,36]$ and anti-PD-1 $[37,38]$ treatments showed interesting results in animals and lymphoma patients. Possibly, this approach may become increasingly successful, similar to the progress in patients with melanoma, lung, and kidney cancers [39-42].

Allogeneic HSCT provides the patient with the immunological graft antilymphoma effect that is not necessarily linked with a graft versus host reactivity [43]. It leads to a plateau in tumor free survival and provides a chance of cure in advanced stage FL [2-4]. In nonmyeloablative allogeneic HSCT, the potential curative response of chemorefractory patients who had a conditioning regimen including ${ }^{90}$ Y-ibritumomab, fludarabine, and cyclophosphamide was interpreted as likely being related to the graft versus lymphoma effect, facilitated by an improved initial disease control, provided by radioimmunotherapy (RIT) [2].

Weiner et al. highlighted 3 potential mechanisms for induction of a tumor-antigen-specific immune response [44], namely, antibody dependent cellular cytotoxicity (ADCC), antibody-targeted cross-presentation of tumor antigens [45], and triggering of the anti-idiotypic antibodies [44]. Regarding the latter mechanism, the anti-idiotype antibody response of FL patients after idiotype vaccination was shown to correlate with better overall survival [46]. Such a "vaccinal effect" resulting in the induction of a specific anti-idiotype $\mathrm{T}$ cell response has also been observed after rituximab treatment [47].

Different preclinical studies further highlighted the potential role of rituximab alone or in combination with vaccines in immune stimulation leading to long-term protection in lymphoma models [48-50]. Stimulation of CD8 T cells has been shown to provide long-lasting antitumor immune protection in syngeneic mouse lymphoma [51-53]. Toll-like receptor stimulation in combination with rituximab treatment has been explored in first clinical studies [54, 55].

\section{Single Agent Rituximab Treatment Is Able to Stimulate T Cell Responses}

Single agent rituximab treatment has been studied in different trials [8-11]. Rituximab is particularly attractive due to its capacity to treat B lymphoma while totally sparing $\mathrm{T}$ cells [9]. Rituximab maintenance has been shown to be highly efficient after the second line R-chemotherapy but is currently also proposed after the first line R-chemotherapy with a significant benefit shown in the PRIMA trial [56]. Longlasting complete responses (CR) have been observed in FL patients responding (67\%) in an early SAKK trial to initial, single agent rituximab. $45 \%$ of the responding patients after first line rituximab reached 8 years continued CR when randomized into the rituximab maintenance arm [9], even though rituximab maintenance in this early study consisted of only 4 supplemental antibody injections administered every 2nd month. Long-term responses were also described after rituximab standard treatment alone [10].

Upon rituximab treatment of lymphoma, activation of NK cells occurs [57] and presence of high numbers of CD4 and CD8 T cells has been shown as being favorable [58]. CD4 $\mathrm{T}$ helper cells, CD8 T cells, and NK cells remained stable under rituximab treatment while helper and NK cells were significantly associated with response and EFS, respectively [59]. A lymphoma idiotype-specific $\mathrm{T}$ cell response was described for FL patients treated by rituximab alone, suggesting that this therapy might also act as a vaccine [47]. Tumorinfiltrating T-helper cells are repressed in the tumor environment as compared with the same population in normal lymph nodes, however, it was shown that they retain their polyfunctional potential to respond to vaccinal stimulation [60]. These observations clearly indicate that rituximab can stimulate the patient's antilymphoma T cell response.

Possibly, another set of T cells, the $\gamma \delta \mathrm{T}$ cells may be involved in FL immunity $[61,62]$. Rituximab could potentially play an enhancing role with regard to these cells as well $[63,64]$. Furthermore, under combined treatment with rituximab and interferon- $\alpha$ [65], the presence of $\mathrm{CD}^{+}$and $\mathrm{CD}^{+} \mathrm{T}$ cells was shown to be favorable while in a different study interferon was able to abrogate the negative effect of IL4 on immune cells [58].

Elimination of regulatory B cells $\left(B_{\text {reg }}, B 10\right)$ could be a further explanation to the observation of $\mathrm{T}$ cell responses under rituximab treatment $[24,34]$. In mice, such Il-10 
producing B10 cells inhibited lymphoma clearance during anti-CD20 immunotherapy. Stimulation of effector T cells with a TLR3 agonist was able to overcome the negative regulatory effects of B10 cells [34]. Since B10 cells are at least partially eliminated by the anti-CD20 therapy, the B cell mediated immunesuppression may be abrogated or at least weakened.

\section{Single Agent or Consolidation RIT Induces Long-Term CR at High Frequency}

RIT has been shown to be an effective single agent therapy at conventional, nonmyeloablative dosing as well as in high dose therapy both in patients in relapse $[6,7,66]$ and as an initial treatment $[12,67]$. RIT consolidation after chemotherapy was shown to convert high numbers of partial remissions (PR) into $\mathrm{CR}$ and to provide prolonged progression free survival $[68,69]$, the latter being also confirmed at the molecular level $[14,70]$. Regarding the upfront, single agent RIT with ${ }^{131} \mathrm{I}-$ tositumomab [12], a 40\% 10-year relapse free survival was reported [13]. While anti-CD20 directed RIT also reduced $\mathrm{B}$ cells, $\mathrm{T}$ cell responses in these patients appeared to be preserved [12]. We observed similarly long-lasting CR in a small series of relapsed indolent lymphoma patients treated between 1999 and 2001 with ${ }^{131}$ I-tositumomab [71], with 6 out of 12 patients showing continued CR at currently 12 years after RIT [72].

The particular high efficacy of RIT is probably not explained by the delivered radiation dose or by the 2 injections of anti-CD20 antibody given at reduced dose. Rather, the combination of both may be important. Indeed, it has been shown that irradiation can contribute to the induction of durable antitumor response in mouse models of lymphoma $[52,53]$. It seems thus reasonable to hypothesize that the longterm efficacy of RIT is dependent on the activation and/or the functional preservation of the patient's T cell antilymphoma response $[12,13]$. Furthermore, the fact that the two approved anti-CD20 antibodies, tositumomab, and ibritumomab are of murine origin implies that the tumor cells are targeted with murine antigens, which can be recognized in their processed form by the patient's $\mathrm{T}$ lymphocytes [73] via crosspresentation by antigen presenting cells, possibly together with antigens from dying tumor cells [45]. CRs induced by RIT might liberate the patient's T cells immunity from the immunosuppressive state imposed by live tumor masses [26] and $B_{\text {reg }}$ cells [24].

\section{The Combination of Two Efficient Antibody Based Treatments May Limit Toxicity While the Long-Term Application (Maintenance) of Rituximab Should Favor the Development of an Immune Response}

Major efforts in cancer treatment are currently directed into development of immunotherapy. In this respect, one might consider rituximab treatment as a lucky punch since rituximab treatment is efficient in patients, has moderate side effects, and has been shown to activate NK cells [57].
Rituximab can have a vaccination effect inducing antiidiotype $T$ cell responses [47], and rituximab treatment alone is able to lead to long-lasting CR in FL patients [9]. While the underlying mechanisms of the efficacy of rituximab are not yet clearly elucidated, it might well be multifunctional beyond $\mathrm{T}$ cells responses.

There are different reasons to combine RIT with rituximab maintenance. First, long-term results have been described for both treatments. Both treatments are of moderate toxicity and present a favorable potential of immune response triggering. RIT tumor bulk reduction is known to be highly efficient and could thus potentially reduce tumor mediated immunesuppression. RIT in combination with a long-term treatment, such as rituximab maintenance known to trigger the immune system, could also have a higher chance to build up a robust antitumor immune response and lead to longer recurrence free survival.

We hypothesize that the patient's $\mathrm{T}$ cells would mediate the long term efficacy of rituximab and RIT. This hypothesis is only supported by indirect evidence of observations in patients and preclinical studies. Nevertheless, different studies have shown that rituximab can stimulate the patient's $T$ cells and have a vaccination effect while preclinical studies have shown that such effects can be decisive for cure in syngeneic mouse models. In that sense the hypothesis of a major $\mathrm{T}$ cell involvement in antibody treatment of FL joins other effects of rituximab that is clearly able to elicit direct apoptosis, ADCC, CDC, or opsonization, although it remains to be determined which of these mechanisms are decisive in patients. Regarding RIT, we argue that the radiation dose given to tumor with nonmyeloablative RIT and the 2 modest amounts of unlabeled antibody are most likely insufficient to explain its long-term efficacy when given as monotherapy upfront [13] or in relapse [69] of FL or indolent lymphoma. These long-term efficacies of RIT and rituximab in indolent lymphoma, a disease that cannot be cured in its advanced form by conventional treatment, prompt the search of different mechanisms of efficacy than the common ones.

Induction R-chemotherapy such as R-CVP, R-CHOP, $\mathrm{R}-\mathrm{MCP}$, and R-CHVP+I has been studied in large, randomized phase III trials in comparison with chemotherapy alone and has shown the advantage of adding rituximab to chemotherapy leading to improved PFS and frequently also OS [74-77], as recently discussed [78]. Adding 2-year rituximab maintenance to such induction therapy was shown in a large phase III trial to improve PFS [56]. Two recent phase III trials showed at least a similar efficacy for combined R-bendamustin treatment compared with R-CHOP $[79,80]$.

In view of the particular high and reliable efficacy of adding rituximab to different chemotherapies and further using it in maintenance, it is intriguing that maintenance treatment with anti-CD20 antibodies has not yet been evaluated in combination with RIT, possibly because RIT and rituximab are developed with different perspectives. An ongoing phase II study (NCT00770224) piloted by SWOG investigates the combined approach of R-CHOP induction chemotherapy 
followed by ${ }^{131}$ I-tositumomab consolidation and 4-year rituximab maintenance. First, results of a similar front line study combining R-CHOP followed by ${ }^{90}$ Y-radioimmunotherapy and maintenance rituximab over 2 years showed a sustained immune response with regard to $\mathrm{T}$ cell counts and memory immune responses while B cells were repressed [81]. A high number of long-term molecular remissions in FL patients were reported in that study as well [81].

Radioimmunotherapy in the upfront setting has shown a remarkable capacity to induce high numbers of long-lasting CR. While R-CHOP combined with rituximab maintenance is currently a well-established upfront treatment, the combination of RIT with rituximab has never been studied. RIT is frequently seen as an alternative therapy to rituximab $[82,83]$. This is also the case in a new randomized study that compares rituximab treatment with ${ }^{131}$ I-tositumomab therapy in relapsed FL patients (NCT00078598). However, rituximab treatment is a unique biological treatment with minor toxicity given under R-chemotherapy and in maintenance [84-87]. Clearly, RIT as a single step therapy involves a different therapeutic mechanism than rituximab maintenance. Furthermore, RIT presents the unique capacity of inducing high numbers of $\mathrm{CR}$ and of converting PR into CR when used in consolidation. This induction of CR notably may be important for the recovery of an effective $T$ cell response since large tumors are able to inhibit the functioning of T cells [88-91].

Different studies have shown that therapeutic options for FL remain open after RIT, including as well collection and transplantation of HSCT [92]. Furthermore, large studies have shown that MDS incidence is not increased after RIT $[93,94]$ but might rather be related to combination with preceding chemotherapies, particularly when these include fludarabine $[95,96]$.

Based on the hypothesis that a preserved or stimulated $\mathrm{T}$ cell response mediates long-term CR of FL, we argue that the unique capacity of RIT of inducing high numbers of long-lasting CR by its own, particularly when used upfront $[12,13]$, would merit to be evaluated in combination with maintenance by rituximab or another anti-CD20 antibody [97-99], possibly double antibody treatment $[100,101]$ or with adjunction of interferon- $\alpha$ [65]. Such combinations may have only moderate toxicity for the patient himself and his $\mathrm{T}$ cells and may be most beneficial in previously untreated patients.

Further insight should be obtained by direct monitoring of the patient's lymphoma specific T cells in RIT studies combined with rituximab maintenance. In parallel, other components of the immune system should also be analyzed, particularly B cells, to determine to which degree they remain repressed over prolonged periods after rituximab treatment, as suggested already from the early single agent rituximab study SAKK 35/98 [9] and others [102]. One could hypothesize that the patient's T cell response would possibly be able to eradicate or at least control FL progenitor cells under such a combination of RIT with rituximab [103], a hypothesis supported by the observation of long-term CR after single agent rituximab and single agent RIT.

\section{Conclusion}

We would expect that the combination of RIT with anti-CD20 antibody maintenance in the early treatment of FL has the potential to be most efficient due to the preservation or/and stimulation of the patient's antitumor T cells response. The addition of anti-PD-1 or anti-CTLA-4 antibodies may further enhance immune responses by reducing inhibitory pathways and regulatory cells. Indeed, consistent and repeated $\mathrm{T}$ cell stimulation may be achieved by RIT with its capacity to induce high numbers of $\mathrm{CR}$, combined with rituximab maintenance capable of maintaining such CR. This approach may therefore be well suited as novel and readily feasible perspective towards potential cure of FL.

\section{Abbreviations}

$\begin{array}{ll}\text { FL: } & \text { Follicular lymphoma } \\ \text { RIT: } & \text { Radioimmunotherapy } \\ \text { CR: } & \text { Complete response } \\ \text { PR: } & \text { Partial response } \\ \text { HSCT: } & \text { Hematopoietic stem cells transplantation } \\ \text { RT-PCR: } & \text { Real-time polymerase chain reaction } \\ \text { ADCC: } & \text { Antibody dependent cellular cytotoxicity } \\ \text { CDC: } & \text { Complement dependent cytotoxicity } \\ \text { SAKK: } & \text { "Schweizerische Arbeitsgemeinschaft für } \\ & \text { klinische Krebsforschung" (Swiss Society } \\ & \text { for Clinical Cancer Research) } \\ \text { R-CVP: } & \text { Rituximab, cyclophosphamide, } \\ & \text { vincristine, and prednisone } \\ \text { R-CHOP: } & \text { Rituximab, cyclophosphamide, } \\ & \text { doxorubicin, vincristine, and prednisone } \\ \text { R-MCP: } & \text { Rituximab-mitoxantrone, chlorambucil, } \\ & \text { and prednisolone } \\ \text { R-CHVP+I: } & \text { Rituximab, cyclophosphamide, } \\ \text { doxorubicin, etoposide, and prednisolone }\end{array}$

\section{Authors' Contribution}

Franz Buchegger and Daniel E. Speiser initiated the writing of this review. Franz Buchegger, Steven M. Larson, Jean-Pierre Mach, Yves Chalandon, Pierre-Yves Dietrich, Anne Cairol, John O. Prior, Pedro Romero, and Daniel E. Speiser then discussed, contributed further evidence, and corrected the paper. All authors approved the final version of the paper.

\section{Acknowledgments}

Yves Chalandon and Pierre-Yves Dietrich have received financial support from Roche Pharmaceutical for formation congresses and participation in board meetings. The other authors declare that there is no conflict of interests.

\section{References}

[1] C. Ujjani and B. D. Cheson, "The optimal management of follicular lymphoma: an evolving field," Drugs, vol. 73, no. 13, pp. 1395-1403, 2013. 
[2] I. F. Khouri, R. M. Saliba, W. D. Erwin et al., "Nonmyeloablative allogeneic transplantation with or without (90)yttrium ibritumomab tiuxetan is potentially curative for relapsed follicular lymphoma: 12-year results," Blood, vol. 119, pp. 6373-6378, 2012.

[3] P. J. Bierman, J. W. Sweetenham, F. R. Loberiza Jr. et al., "Syngeneic hematopoietic stem-cell transplantation for non-Hodgkin's lymphoma: a comparison with allogeneic and autologous transplantation: the Lymphoma Working Committee of the International Bone Marrow Transplant Registry and the European Group for Blood and Marrow Transplantation," Journal of Clinical Oncology, vol. 21, no. 20, pp. 3744-3753, 2003.

[4] M. Ghielmini, "Follicular lymphoma," Annals of Oncology, vol. 21, supplement 7, pp. vii151-vii153, 2010.

[5] O. Ringdén, H. Karlsson, R. Olsson, B. Omazic, and M. Uhlin, "The allogeneic graft-versus-cancer effect," British Journal of Haematology, vol. 147, no. 5, pp. 614-633, 2009.

[6] O. W. Press, J. F. Eary, F. R. Appelbaum et al., "Radiolabeledantibody therapy of B-cell lymphoma with autologous bone marrow support," The New England Journal of Medicine, vol. 329, no. 17, pp. 1219-1224, 1993.

[7] M. S. Kaminski, K. R. Zasadny, I. R. Francis et al., "Radioimmunotherapy of B-cell lymphoma with [131I]anti-B1 (antiCD20) antibody," The New England Journal of Medicine, vol. 329, no. 7, pp. 459-465, 1993.

[8] M. Ghielmini, S. H. Schmitz, S. B. Cogliatti et al., "Prolonged treatment with rituximab in patients with follicular lymphoma significantly increases event-free survival and response duration compared with the standard weekly $\times 4$ schedule," Blood, vol. 103, no. 12, pp. 4416-4423, 2004.

[9] G. Martinelli, S. H. Schmitz, U. Utiger et al., "Long-term followup of patients with follicular lymphoma receiving single-agent rituximab at two different schedules in trial SAKK 35/98," Journal of Clinical Oncology, vol. 28, no. 29, pp. 4480-4484, 2010.

[10] P. Colombat, N. Brousse, G. Salles et al., "Rituximab induction immunotherapy for first-line low-tumor-burden follicular lymphoma: survival analyses with 7-year follow-up," Annals of Oncology, vol. 23, pp. 2380-2385, 2012.

[11] T. E. Witzig, A. M. Vukov, T. M. Habermann et al., "Rituximab therapy for patients with newly diagnosed, advanced-stage, follicular grade I non-Hodgkin's lymphoma: a phase II trial in the North Central Cancer Treatment Group," Journal of Clinical Oncology, vol. 23, no. 6, pp. 1103-1108, 2005.

[12] M. S. Kaminski, M. Tuck, J. Estes et al., "131I-tositumomab therapy as initial treatment for follicular lymphoma," The New England Journal of Medicine, vol. 352, no. 5, pp. 441-449, 2005.

[13] M. S. Kaminski, M. Tuck, J. Estes et al., "Tositumomab and Iodine I-131 Tositumomab for previously untreated, advancedstage, follicular lymphoma: median 10 year follow-up results," Blood, vol. 114, p. 3759, 2009, (Abstract).

[14] L. Goff, K. Summers, S. Iqbal et al., "Quantitative PCR analysis for Bcl-2/IgH in a phase III study of yttrium-90 ibritumomab tiuxetan as consolidation of first remission in patients with follicular lymphoma," Journal of Clinical Oncology, vol. 27, no. 36, pp. 6094-6100, 2009.

[15] F. Buchegger, C. Antonescu, C. Helg et al., "Six of 12 relapsed or refractory indolent lymphoma patients treated 10 years ago with131I-tositumomab remain in complete remission," Journal of Nuclear Medicine, vol. 52, no. 6, pp. 896-900, 2011.

[16] F. Buchegger, J. P. Mach, O. W. Press et al., "Improving the chance of cure of follicular lymphoma by combining immunotherapy and radioimmunotherapy based on anti-CD20 antibodies?" Annals of Oncology, vol. 24, pp. 1948-1949, 2013.

[17] B. E. Wahlin, B. Sander, B. Christensson et al., "Entourage: the immune microenvironment following follicular lymphoma," Blood Cancer Journal, vol. 2, p. e52, 2012.

[18] F. Guilloton, G. Caron, C. Ménard et al., "Mesenchymal stromal cells orchestrate follicular lymphoma cell niche through the CCL2-dependent recruitment and polarization of monocytes," Blood, vol. 119, no. 11, pp. 2556-2567, 2012.

[19] R. Kridel, L. H. Sehn, and R. D. Gascoyne, "Pathogenesis of follicular lymphoma," Journal of Clinical Investigation, vol. 122, pp. 3424-3431, 2012.

[20] L. Li, J. Cole, and D. A. Margolin, "Cancer stem cell and stromal microenvironment," The Ochsner Journal, vol. 13, pp. 109-118, 2013.

[21] C. Laurent, S. Müller, C. Do et al., "Distribution, function, and prognostic value of cytotoxic $\mathrm{T}$ lymphocytes in follicular lymphoma: a 3-D tissue-imaging study," Blood, vol. 118, no. 20, pp. 5371-5379, 2011.

[22] A. G. Ramsay and J. G. Gribben, "The kiss of death in FL," Blood, vol. 118 , no. 20 , pp. 5365-5366, 2011.

[23] T. Kelley, R. Beck, A. Absi, T. Jin, B. Pohlman, and E. Hsi, "Biologic predictors in follicular lymphoma: importance of markers of immune response," Leukemia and Lymphoma, vol. 48, no. 12, pp. 2403-2411, 2007.

[24] D. J. Dilillo, T. Matsushita, and T. F. Tedder, "B10 cells and regulatory B cells balance immune responses during inflammation, autoimmunity, and cancer," Annals of the New York Academy of Sciences, vol. 1183, pp. 38-57, 2010.

[25] A. Marabelle, H. Kohrt, I. Sagiv-Barfi et al., "Depleting tumorspecific Tregs at a single site eradicates disseminated tumors," Journal of Clinical Investigation, vol. 123, pp. 2447-2463, 2013.

[26] L. Baitsch, P. Baumgaertner, E. Devêvre et al., "Exhaustion of tumor-specific CD8+ T cells in metastases from melanoma patients," Journal of Clinical Investigation, vol. 121, no. 6, pp. 2350-2360, 2011.

[27] Z. Yang, D. M. Grote, S. C. Ziesmer et al., "IL-12 upregulates TIM-3 expression and induces T cell exhaustion in patients with follicular B cell non-Hodgkin lymphoma," Journal of Clinical Investigation, vol. 122, no. 4, pp. 1271-1282, 2012.

[28] S. S. Dave, G. Wright, B. Tan et al., "Prediction of survival in follicular lymphoma based on molecular features of tumor-infiltrating immune cells," The New England Journal of Medicine, vol. 351, pp. 2159-2169, 2004.

[29] R. J. Byers, E. Sakhinia, P. Joseph et al., "Clinical quantitation of immune signature in follicular lymphoma by RT-PCR-based gene expression profiling," Blood, vol. 111, no. 9, pp. 4764-4770, 2008.

[30] J. Carreras, A. Lopez-Guillermo, B. C. Fox et al., "High numbers of tumor-infiltrating FOXP3-positive regulatory $\mathrm{T}$ cells are associated with improved overall survival in follicular lymphoma," Blood, vol. 108, no. 9, pp. 2957-2964, 2006.

[31] J. Wang and X. Ke, "The Four types of Tregs in malignant lymphomas," Journal of Hematology and Oncology, vol. 4, article 50, 2011.

[32] P. Ame-Thomas and K. Tarte, "The yin and the yang of follicular lymphoma cell niches: role of microenvironment heterogeneity and plasticity," Seminars in Cancer Biology, 2013.

[33] S. Rawal, F. Chu, M. Zhang et al., "Cross talk between follicular Th cells and tumor cells in human follicular lymphoma promotes immune evasion in the tumor microenvironment," The Journal of Immunology, vol. 190, pp. 6681-6693, 2013. 
[34] M. Horikawa, V. Minard-Colin, T. Matsushita, and T. F. Tedder, "Regulatory B cell production of IL-10 inhibits lymphoma depletion during CD20 immunotherapy in mice," Journal of Clinical Investigation, vol. 121, no. 11, pp. 4268-4280, 2011.

[35] J. Brody, H. Kohrt, A. Marabelle, and R. Levy, "Active and passive immunotherapy for lymphoma: proving principles and improving results," Journal of Clinical Oncology, vol. 29, no. 14, pp. 1864-1875, 2011.

[36] S. M. Ansell, S. A. Hurvitz, P. A. Koenig et al., "Phase I study of ipilimumab, an anti-CTLA-4 monoclonal antibody, in patients with relapsed and refractory B-cell non-Hodgkin lymphoma," Clinical Cancer Research, vol. 15, no. 20, pp. 6446-6453, 2009.

[37] J. H. Myklebust, J. M. Irish, J. Brody et al., "High PD-1 expression and suppressed cytokine signaling distinguish $\mathrm{T}$ cells infiltrating follicular lymphoma tumors from peripheral $\mathrm{T}$ cells," Blood, vol. 121, pp. 1367-1376, 2013.

[38] P. Armand, A. Nagler, E. A. Weller et al., "Disabling immune tolerance by programmed death-1 blockade with pidilizumab after autologous hematopoietic stem-cell transplantation for diffuse large B-cell lymphoma: results of an international phase II trial," Journal of Clinical Oncology, 2013.

[39] F. S. Hodi, S. J. O’Day, D. F. McDermott et al., "Improved survival with ipilimumab in patients with metastatic melanoma," The New England Journal of Medicine, vol. 363, pp. 711-723, 2010.

[40] J. D. Wolchok, H. Kluger, M. K. Callahan et al., "Nivolumab plus ipilimumab in advanced melanoma," The New England Journal of Medicine, vol. 369, pp. 122-133, 2013.

[41] S. L. Topalian, F. S. Hodi, J. R. Brahmer et al., "Safety, activity, and immune correlates of anti-PD-1 antibody in cancer," The New England Journal of Medicine, vol. 366, pp. 2443-2454, 2012.

[42] O. Hamid, C. Robert, A. Daud et al., "Safety and tumor responses with lambrolizumab (anti-PD-1) in melanoma," The New England Journal of Medicine, vol. 369, pp. 134-144, 2013.

[43] A. Lask, E. Ophir, N. Or-Geva et al., "A new approach for eradication of residual lymphoma cells by host nonreactive antithird-party central memory CD8 T cells," Blood, vol. 121, pp. 3033-3040, 2013.

[44] L. M. Weiner, M. V. Dhodapkar, and S. Ferrone, "Monoclonal antibodies for cancer immunotherapy," The Lancet, vol. 373, no. 9668, pp. 1033-1040, 2009.

[45] N. Selenko, O. Majdic, U. Jäger, C. Sillaber, J. Stöckl, and W. Knapp, "Cross-priming of cytotoxic T cells promoted by apoptosis-inducing tumor cell reactive antibodies?" Journal of Clinical Immunology, vol. 22, no. 3, pp. 124-130, 2002.

[46] W. Z. Ai, R. Tibshirani, B. Taidi, D. Czerwinski, and R. Levy, "Anti-idiotype antibody response after vaccination correlates with better overall survival in follicular lymphoma," Blood, vol. 113, no. 23, pp. 5743-5746, 2009.

[47] S. P. Hilchey, O. Hyrien, T. R. Mosmann et al., "Rituximab immunotherapy results in the induction of a lymphoma idiotype-specific T-cell response in patients with follicular lymphoma: support for a "vaccinal effect" of rituximab," Blood, vol. 113, no. 16, pp. 3809-3812, 2009.

[48] R. Abès, E. Gélizé, W. H. Fridman, and J. Teillaud, "Long-lasting antitumor protection by anti-CD20 antibody through cellular immune response," Blood, vol. 116, no. 6, pp. 926-934, 2010.

[49] Z. Gadri, T. Kukulansky, E. Bar-Or, J. Haimovich, and N. Hollander, "Synergistic effect of dendritic cell vaccination and antiCD20 antibody treatment in the therapy of murine lymphoma," Journal of Immunotherapy, vol. 32, no. 4, pp. 333-340, 2009.
[50] S. Manzur, S. Cohen, J. Haimovich, and N. Hollander, "Enhanced therapeutic effect of B cell-depleting anti-CD20 antibodies upon combination with in-situ dendritic cell vaccination in advanced lymphoma," Clinical and Experimental Immunology, vol. 170, pp. 291-299, 2012.

[51] B. Varghese, A. Widman, J. Do et al., "Generation of CD8+ T cell-mediated immunity against idiotype-negative lymphoma escapees," Blood, vol. 114, no. 20, pp. 4477-7785, 2009.

[52] S. J. Dovedi, M. H. Melis, R. W. Wilkinson et al., "Systemic delivery of a TLR7 agonist in combination with radiation primes durable antitumor immune responses in mouse models of lymphoma," Blood, vol. 121, pp. 251-259, 2013.

[53] J. Honeychurch, M. H. Melis, S. J. Dovedi, L. Mu, and T. M. Illidge, "Immunogenic potential of irradiated lymphoma cells is enhanced by adjuvant immunotherapy and modulation of local macrophage populations," Leukemia \& Lymphoma, vol. 54, pp. 2008-2015, 2013.

[54] J. W. Friedberg, J. L. Kelly, D. Neuberg et al., "Phase II study of a TLR-9 agonist (1018 ISS) with rituximab in patients with relapsed or refractory follicular lymphoma," British Journal of Haematology, vol. 146, no. 3, pp. 282-291, 2009.

[55] J. P. Leonard, B. K. Link, C. Emmanouilides et al., "Phase I trial of toll-like receptor 9 agonist PF-3512676 with and following rituximab in patients with recurrent indolent and aggressive non-Hodgkin's lymphoma," Clinical Cancer Research, vol. 13, no. 20, pp. 6168-6174, 2007.

[56] G. Salles, J. F. Seymour, F. Offner et al., "Rituximab maintenance for 2 years in patients with high tumour burden follicular lymphoma responding to rituximab plus chemotherapy (PRIMA): a phase 3, randomised controlled trial," The Lancet, vol. 377, pp. 42-51, 2011.

[57] S. Veeramani, S. Wang, C. Dahle et al., "Rituximab infusion induces NK activation in lymphoma patients with the highaffinity CD16 polymorphism," Blood, vol. 118, no. 12, pp. 33473349, 2011.

[58] B. E. Wahlin, C. Sundström, H. Holte et al., "T cells in tumors and blood predict outcome in follicular lymphoma treated with rituximab," Clinical Cancer Research, vol. 17, no. 12, pp. 41364144, 2011.

[59] M. Ghielmini, K. Rufibach, G. Salles et al., "Single agent rituximab in patients with follicular or mantle cell lymphoma: clinical and biological factors that are predictive of response and event-free survival as well as the effect of rituximab on the immune system: a study of the Swiss Group for Clinical Cancer Research (SAKK)," Annals of Oncology, vol. 16, no. 10, pp. 1675$1682,2005$.

[60] S. P. Hilchey, A. F. Rosenberg, O. Hyrien et al., "Follicular lymphoma tumor-infiltrating T-helper (TH) cells have the same polyfunctional potential as normal nodal $\mathrm{TH}$ cells despite skewed differentiation," Blood, vol. 118, no. 13, pp. 3591-3602, 2011.

[61] J. J. Fournie, H. Sicard, M. Poupot et al., "What lessons can be learned from gammadelta $\mathrm{T}$ cell-based cancer immunotherapy trials?" Cellular \& Molecular Immunology, vol. 10, pp. 35-41, 2013.

[62] M. S. Braza, A. Caraux, T. Rousset et al., "Gammadelta T lymphocytes count is normal and expandable in peripheral blood of patients with follicular lymphoma, whereas it is decreased in tumor lymph nodes compared with inflammatory lymph nodes," The Journal of Immunology, vol. 184, no. 1, pp. 134-140, 2010. 
[63] H. Tokuyama, T. Hagi, S. R. Mattarollo et al., "V gamma $9 \mathrm{~V}$ delta $2 \mathrm{~T}$ cell cytotoxicity against tumor cells is enhanced by monoclonal antibody drugs: rituximab and trastuzumab," International Journal of Cancer, vol. 122, pp. 2526-2534, 2008.

[64] J. Gertner-Dardenne, C. Bonnafous, C. Bezombes et al., "Bromohydrin pyrophosphate enhances antibody-dependent cell-mediated cytotoxicity induced by therapeutic antibodies," Blood, vol. 113, no. 20, pp. 4875-4884, 2009.

[65] E. Kimby, "Biological therapy doublets: pairing rituximab with interferon, lenalidomide, and other biological agents in patients with follicular lymphoma," Current Hematologic Malignancy Reports, vol. 7, pp. 221-227, 2012.

[66] T. E. Witzig, A. Molina, L. I. Gordon et al., "Long-term responses in patients with recurring or refractory B-cell non-Hodgkin lymphoma treated with yttrium 90 ibritumomab tiuxetan," Cancer, vol. 109, no. 9, pp. 1804-1810, 2007.

[67] C. W. Scholz, A. Pinto, W. Linkesch et al., “(90)Yttriumibritumomab-tiuxetan as first-line treatment for follicular lymphoma: 30 months of follow-up data from an international multicenter phase II clinical trial," Journal of Clinical Oncology, vol. 31, pp. 308-313, 2013.

[68] F. Morschhauser, J. Radford, A. Van Hoof et al., "Phase III trial of consolidation therapy with yttrium-90-ibritumomab tiuxetan compared with no additional therapy after first remission in advanced follicular lymphoma," Journal of Clinical Oncology, vol. 26, no. 32, pp. 5156-5164, 2008.

[69] F. Morschhauser, J. Radford, A. Van Hoof et al., “(90)Yttriumibritumomab tiuxetan consolidation of first remission in advanced-stage follicular non-Hodgkin lymphoma: updated results after a median follow-up of 7. 3 years from the International, Randomized, Phase III First-LineIndolent trial," Journal of Clinical Oncology, vol. 31, pp. 1977-1983, 2013.

[70] N. M. Pennell, M. Cheung, L. K. Hicks et al., "First evidence for high incidence of complete and sustained molecular remissions and maintenance of immune responses in patients receiving consolidation with Y90 Ibritumomab Tiuxetan ((90)Y-RIT) post R-CHOP for newly diagnosed advanced stage high and intermediate risk follicular lymphoma," Blood, vol. 118, Abstract 2701, 2011.

[71] F. Buchegger, C. Antonescu, A. Bischof Delaloye et al., "Longterm complete responses after 131I-tositumomab therapy for relapsed or refractory indolent non-Hodgkin's lymphoma," British Journal of Cancer, vol. 94, no. 12, pp. 1770-1776, 2006.

[72] F. Buchegger, C. Antonescu, C. Helg et al., "Long-term followup after 131I-tositumomab therapy for relapsed or refractory indolent non-Hodgkin's lymphoma: an update at 12 years," Nuclear Medicine, vol. 52, p. A114, 2013, (Abstract).

[73] A. Lanzavecchia, S. Abrignani, D. Scheidegger, R. Obrist, B. Dorken, and G. Moldenhauer, "Antibodies as antigens. The use of mouse monoclonal antibodies to focus human T cells against selected targets," Journal of Experimental Medicine, vol. 167, no. 2, pp. 345-352, 1988.

[74] R. Marcus, K. Imrie, P. Solal-Celigny et al., "Phase III study of RCVP compared with cyclophosphamide, vincristine, and prednisone alone in patients with previously untreated advanced follicular lymphoma," Journal of Clinical Oncology, vol. 26, no. 28, pp. 4579-4586, 2008.

[75] W. Hiddemann, M. Kneba, M. Dreyling et al., "Frontline therapy with rituximab added to the combination of cyclophosphamide, doxorubicin, vincristine, and prednisone (CHOP) significantly improves the outcome for patients with advancedstage follicular lymphoma compared with therapy with $\mathrm{CHOP}$ alone: results of a prospective randomized study of the German Low-Grade Lymphoma Study Group," Blood, vol. 106, no. 12, pp. 3725-3732, 2005.

[76] M. Herold, A. Haas, S. Srock et al., "Rituximab added to firstline mitoxantrone, chlorambucil, and prednisolone chemotherapy followed by interferon maintenance prolongs survival in patients with advanced follicular lymphoma: an East German study group hematology and oncology study," Journal of Clinical Oncology, vol. 25, no. 15, pp. 1986-1992, 2007.

[77] G. Salles, N. Mounier, S. de Guibert et al., "Rituximab combined with chemotherapy and interferon in follicular lymphoma patients: results of the GELA-GOELAMS FL2000 study," Blood, vol. 112, no. 13, pp. 4824-4831, 2008.

[78] O. W. Press and M. C. Palanca-Wessels, "Selection of first-line therapy for advanced follicular lymphoma," Journal of Clinical Oncology, vol. 31, pp. 1496-1497, 2013.

[79] M. J. Rummel, N. Niederle, G. Maschmeyer et al., "Bendamustine plus rituximab versus CHOP plus rituximab as firstline treatment for patients with indolent and mantle-cell lymphomas: an open-label, multicentre, randomised, phase 3 noninferiority trial," The Lancet, vol. 381, pp. 1203-1210, 2013.

[80] I. W. Flinn, R. H. Van der Jagt, B. S. Kahl et al., "An openlabel, randomized study of Bendamustine and Rituximab (BR) compared with Rituximab, Cyclophosphamide, Vincristine and Prednisone (R-CVP) or Rituximab, Cyclophoasphamide, Doxorubicin, Vincristine and Prednisone (R-CHOP) in first-line tretment of patients with advanced indolent non-Hodgkin's lymphoma (NHL) or mantle cell lymphomas (MCL). The Bright study," Blood, vol. 120, Abstract 902, 2012.

[81] N. L. Berinstein, N. M. Pennell, M. A. Cussen et al., "Sustained immune compentency and long term molecular remissions in FL patients with FLIPI risk factors $>1$, treated front line with RCHOP followed by consolidative (90)Y-radioimmunotherapy and maintenance rituximab," Blood, vol. 120, Abstract 3681, 2012.

[82] T. E. Witzig, L. I. Gordon, F. Cabanillas et al., "Randomized controlled trial of yttrium-90-labeled ibritumomab tiuxetan radioimmunotherapy versus rituximab immunotherapy for patients with relapsed or refractory low-grade, follicular, or transformed B-cell non-Hodgkin's lymphoma," Journal of Clinical Oncology, vol. 20, no. 10, pp. 2453-2463, 2002.

[83] O. W. Press, J. M. Unger, L. M. Rimsza et al., "Phase III randomized intergroup trial of $\mathrm{CHOP}$ plus rituximab compared with CHOP chemotherapy plus (131)iodine-tositumomab for previously untreated follicular non-Hodgkin lymphoma: SWOG S0016," Journal of Clinical Oncology, vol. 31, pp. 314-320, 2013.

[84] M. Ghielmini, U. Vitolo, E. Kimby et al., "ESMO Guidelines consensus conference on malignant lymphoma 2011 part 1: diffuse large B-cell lymphoma (DLBCL), follicular lymphoma (FL) and chronic lymphocytic leukemia (CLL)," Annals of Oncology, vol. 24, pp. 561-576, 2013.

[85] P. L. Zinzani, M. Marchetti, A. Billio et al., "SIE, SIES, GITMO revised guidelines for the management of follicular lymphoma," American Journal of Hematology, vol. 88, pp. 185-192, 2013.

[86] C. McNamara, J. Davies, M. Dyer et al., "Guidelines on the investigation and management of follicular lymphoma," British Journal of Haematology, vol. 156, no. 4, pp. 446-467, 2012.

[87] J. Yared, A. Kimball, M. R. Baer, H. Bahrain, and M. Auerbach, "Rituximab maintenance therapy until progression after rituximab and chemotherapy induction in patients with follicular 
lymphoma," Clinical Lymphoma Myeloma and Leukemia, vol. 13, pp. 253-257, 2013.

[88] T. W. Kelley and C. J. Parker, “CD4 (+)CD25 (+)Foxp3 (+) regulatory $\mathrm{T}$ cells and hematologic malignancies," Frontiers in Bioscience, vol. 2, pp. 980-992, 2010.

[89] A. Kosmaczewska, L. Ciszak, S. Potoczek, and I. Frydecka, "The significance of Treg cells in defective tumor immunity," Archivum Immunologiae et Therapiae Experimentalis, vol. 56, no. 3, pp. 181-191, 2008.

[90] A. Facciabene, G. T. Motz, and G. Coukos, "T-regulatory cells: key players in tumor immune escape and angiogenesis," Cancer Research, vol. 72, no. 9, pp. 2162-2171, 2012.

[91] L. Baitsch, S. A. Fuertes-Marraco, A. Legat, C. Meyer, and D. E. Speiser, "The three main stumbling blocks for anticancer $\mathrm{T}$ cells," Trends in Immunology, vol. 33, pp. 364-372, 2012.

[92] E. Derenzini, C. Pellegrini, R. Maglie et al., "Collection of hematopoietic stem cells after previous exposure to Yttrium-90 Ibritumomab Tiuxetan (Zevalin) is feasible and does not impair autologous stem cell transplantation outcome in follicular lymphoma," Blood, vol. 120, Abstract 3019, 2012.

[93] J. M. Bennett, M. S. Kaminski, J. P. Leonard et al., "Assessment of treatment-related myelodysplastic syndromes and acute myeloid leukemia in patients with non-Hodgkin lymphoma treated with tositumomab and iodine I131 tositumomab," Blood, vol. 105, no. 12, pp. 4576-4582, 2005.

[94] T. E. Witzig, C. A. White, L. I. Gordon et al., "Safety of yttrium-90 ibritumomab tiuxetan radioimmunotherapy for relapsed low-grade, follicular, or transformed non-Hodgkin's lymphoma," Journal of Clinical Oncology, vol. 21, no. 7, pp. 12631270, 2003.

[95] D. Zimowska-Curylo, W. Jurczak, A. Giza, M. Jakobczyk, K. Krawczyk, and A. B. Skotnicki, "High incidence of tMDS in elederly lymphoma patients subjected to radioimmunotherapy," Blood, vol. 120, Abstract 4882, 2012.

[96] S. Waheed, I. Ferreira, D. A. Katz et al., "Incidence and characteristics of therapy related myeloid neoplasms in patients with non-Hodgkins lymphoma treated with radioimmunotherapy," Blood, vol. 2012, Abstract 4924, 2012.

[97] D. J. Kern, B. R. James, S. Blackwell, C. Gassner, C. Klein, and G. J. Weiner, "GA101 induces NK-cell activation and antibodydependent cellular cytotoxicity more effectively than rituximab when complement is present," Leukemia \& Lymphoma, vol. 54, no. 11, pp. 2500-2505, 2013.

[98] S. A. Beers, C. H. T. Chan, S. James et al., "Type II (tositumomab) anti-CD20 monoclonal antibody out performs type I (rituximab-like) reagents in B-cell depletion regardless of complement activation," Blood, vol. 112, no. 10, pp. 4170-4177, 2008.

[99] W. Alduaij, A. Ivanov, J. Honeychurch et al., "Novel type II anti-CD20 monoclonal antibody (GA101) evokes homotypic adhesion and actin-dependent, lysosome-mediated cell death in B-cell malignancies," Blood, vol. 117, no. 17, pp. 4519-4529, 2011.

[100] M. S. Czuczman, J. P. Leonard, S. Jung et al., "Phase II trial of galiximab (anti-CD80 monoclonal antibody) plus rituximab (CALGB, 50402): Follicular Lymphoma International Prognostic Index (FLIPI) score is predictive of upfront immunotherapy responsiveness," Annals of Oncology, vol. 23, pp. 2356-2362, 2012.

[101] B. W. Grant, S. H. Jung, J. L. Johnson et al., "A phase 2 trial of extended induction epratuzumab and rituximab for previously untreated follicular lymphoma: CALGB, 50701,' Cancer, vol. 119, pp. 3797-3804, 2013.

[102] O. E. Yri, D. Torfoss, O. Hungnes et al., "Rituximab blocks protective serologic response to influenza A (H1N1) 2009 vaccination in lymphoma patients during or within 6 months after treatment," Blood, vol. 118, no. 26, pp. 6769-6771, 2011.

[103] E. Carlotti, D. Wrench, J. Matthews et al., "Transformation of follicular lymphoma to diffuse large B-cell lymphoma may occur by divergent evolution from a common progenitor cell or by direct evolution from the follicular lymphoma clone," Blood, vol. 113, no. 15, pp. 3553-3557, 2009. 


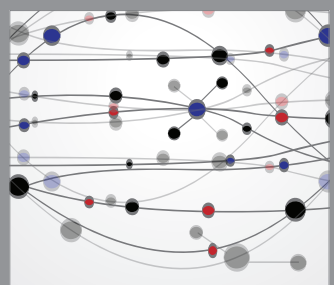

The Scientific World Journal
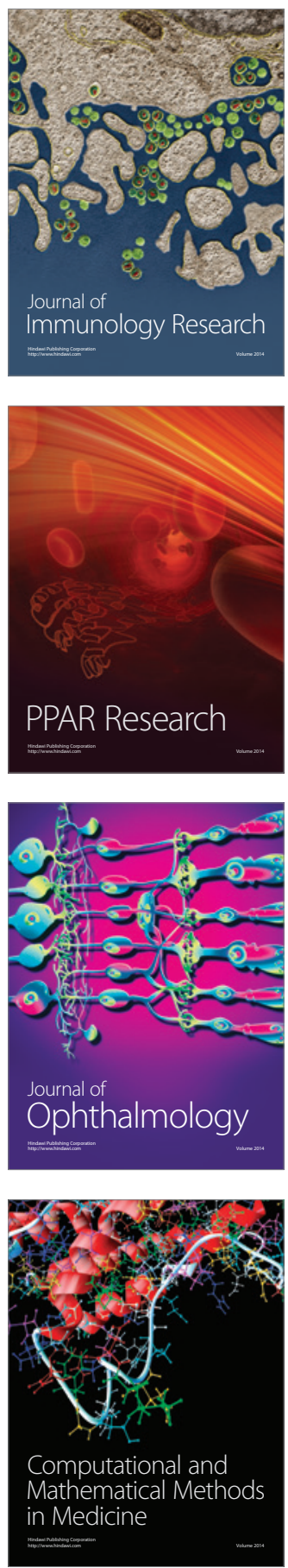

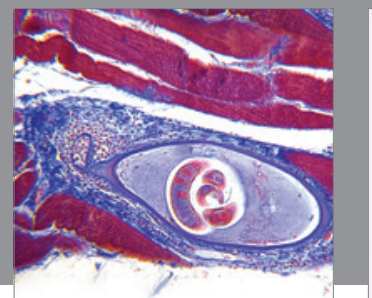

Gastroenterology

Research and Practice
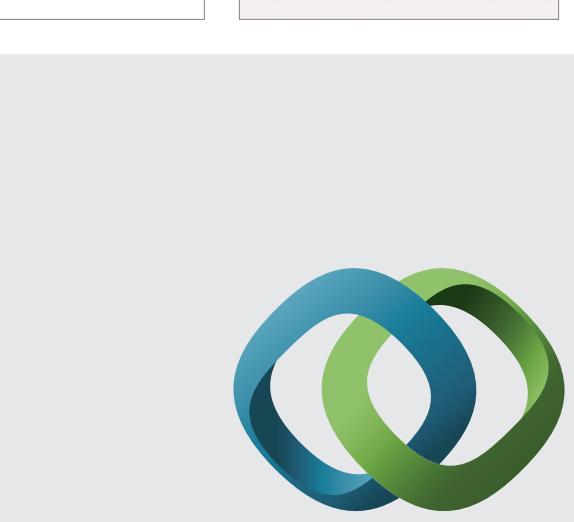

\section{Hindawi}

Submit your manuscripts at

http://www.hindawi.com
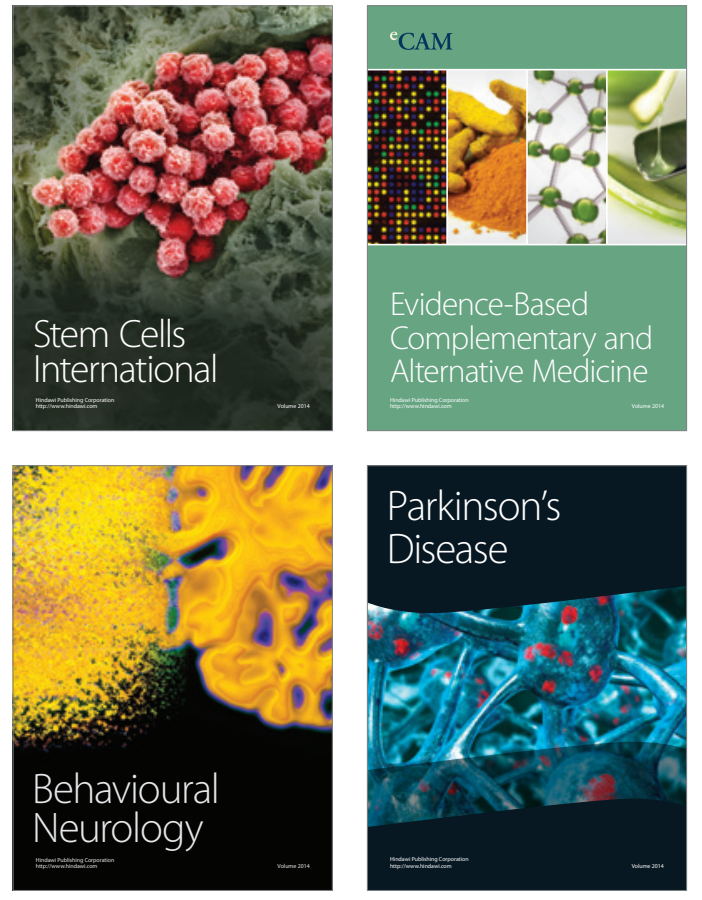
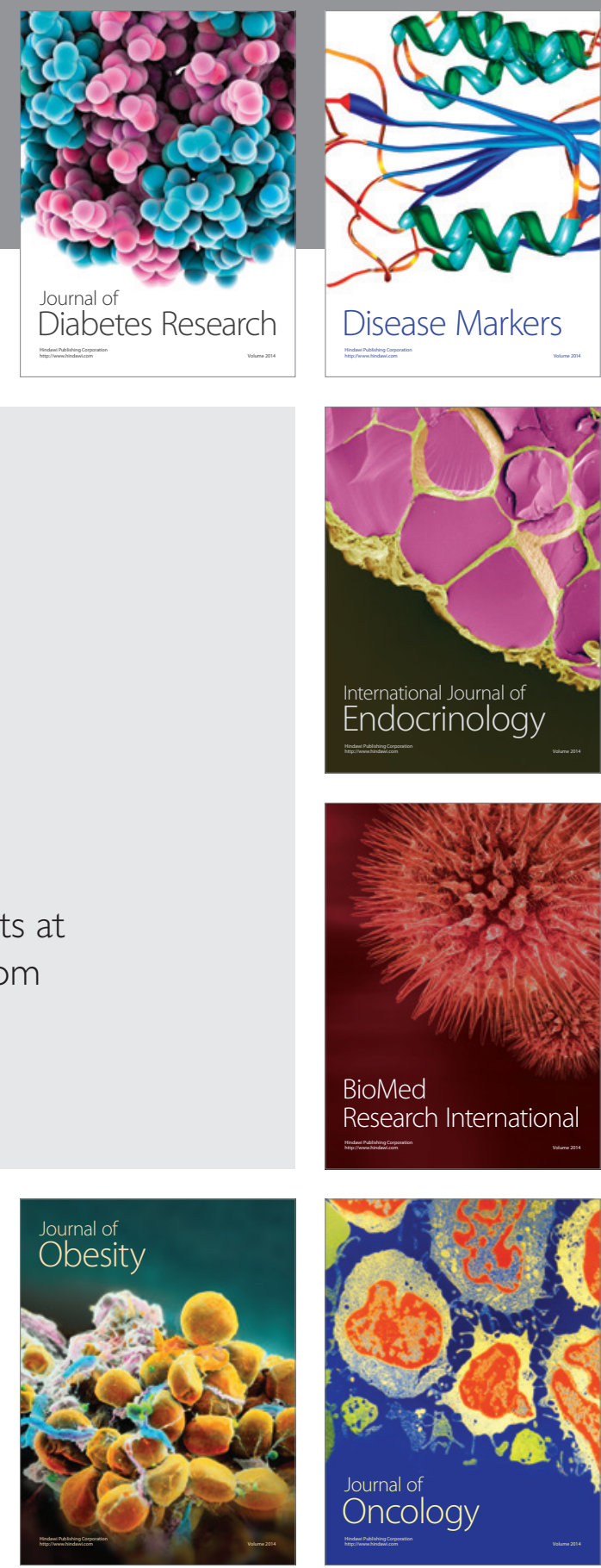

Disease Markers
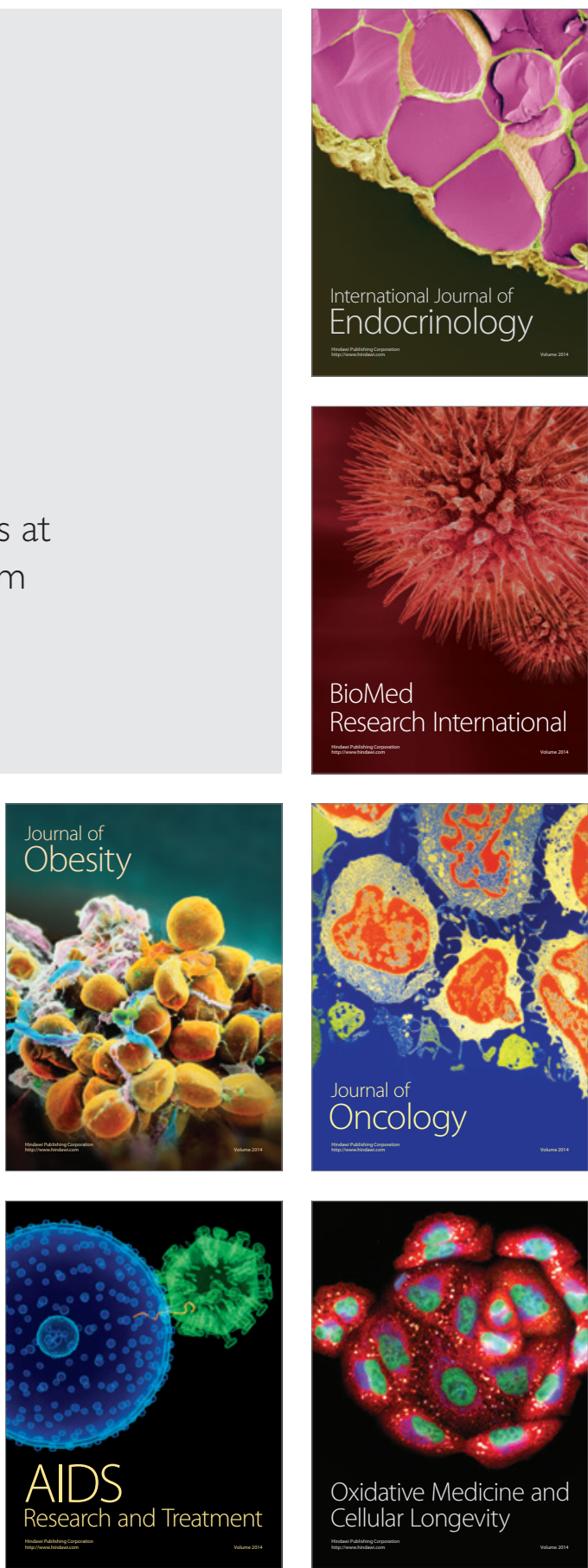